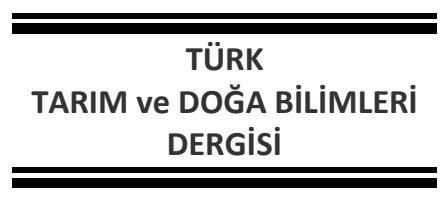

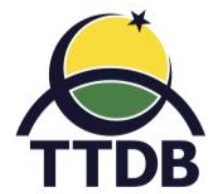

www.dergipark.gov.tr/turkjans

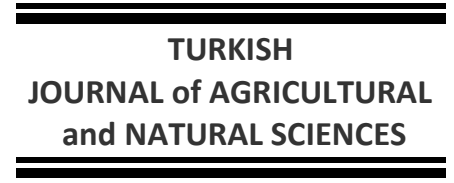

Araştırma Makalesi

\title{
Damla Sulama Sistemi ille Uygulanan Farklı Seviyelerdeki Azotun Washington Navel Portakalında Verim Üzerine Etkisi
}

\author{
Dilek GÜVEN ${ }^{1 *}$, Nuri ARI ${ }^{1}$, Zeynep ERYILMAZ², Cevdet Fehmi ÖZKAN ${ }^{1}$, Filiz OKTUREN ASRi ${ }^{1}$ E.Işıl DEMIRTAŞ ${ }^{1}$, M. \\ Ali ÇELIKYURT ${ }^{3}$ \\ ${ }^{1}$ BATEM, Toprak ve Su Kaynakları Bölümü, Antalya \\ ${ }^{2}$ BATEM, Meyvecilik Bölümü, Antalya \\ ${ }^{3}$ BATEM, Tarım Ekonomisi Bölümü, Antalya \\ *Sorumlu yazar: dilek.guven@tarimorman.gov.tr
}

\begin{abstract}
Geliş Tarihi: 13.04.2018
Düzeltme Geliş Tarihi: 18.09.2018

Kabul Tarihi: 18.09.2018

\section{Özet}

Bu çalışma, Washington Navel portakalında, yüksek verim ve kalite için, damla sulama sistemiyle uygulanması gereken en ekonomik azot dozunun belirlenmesi amacıyla yürütülmüştür. Deneme Antalya Batı Akdeniz Tarımsal Araştırma Enstitüsünde bulunan, turunç anacı üzerine aşılı, 13 yaşındaki Washington Navel ağaçlarında, tesadüf blokları deneme desenine göre 3 tekerrürlü 5 uygulama (0, 350, 700, 1050, 1400 g N/ağaç) olacak şekilde planlanmıştır. Denemede 2011ve 2012 yıllarında uygulamasız ön verimler alınmış, 2013-2014 yıllarında uygulamalar yapılmıştır. Uygulama yapılan yıllarda, Aralık ayında meyvelerin hasatları yapılmış ve ağaç başına düşen verim değerleri saptanmıştır. Araştırma sonucunda verim değerlerinin regresyon analizi yapıldığında sulama suyu ile azotlu gübre uygulamasında (fertigasyon) verim açısından verilmesi gereken optimum dozun $778 \mathrm{~g}$ N/ağaç olduğu saptanmıştır.
\end{abstract}

Anahtar kelimeler: Fertigasyon, verim, kalite, optimum doz.

\section{The Effect of Different Levels of Nitrogen on The Yield of Washington Navel Orange Applied with Drip Irrigation System}

\begin{abstract}
This study was conducted to determine the most economical nitrogen dose to be applied by the drip irrigation system for high yield and quality in the Washington Navel oranges. The experiment was planned to be 5 replications $(0,350,700,1050,1400 \mathrm{~g} \mathrm{~N} /$ tree) in the Washington Navel trees, 13 years old, grafted on the turuncian mother farm, located in the Western Mediterranean Agricultural Research Institute, according to randomized blocks trial design. In the experiment, preliminary applications without application were taken in 2011 and 2012 and applications were made in 2013-2014. During the years of application, fruit harvests were made in December and yield values per tree were determined. As a result of the regression analysis of the yield values, it was determined that the optimum dose to be given in terms of fertilizing efficiency with the irrigation water was $778 \mathrm{~g} \mathrm{~N} /$ tree.
\end{abstract}

Key words: Fertigation, yield, quality, optimum dosage.

Giriş

Turunçgiller turunç, portakal, mandarin, greyfurt, bergamot ve limon gibi ekonomik değeri yüksek olan, Citrus cinsi meyveleri içine alan, tüm dünyada taze olarak tüketiminin yanı sıra meyve suyu ve uçucu yağ endüstrisinde de kullanılan bir bitki grubudur. Meyve içeriğindeki yüksek oranda C vitamini ve mineral maddeler nedeniyle sağlık açısından oldukça iyi bilinen özelliklere de sahiptir. Turunçgiller yaklaşık 136 milyon ton üretim ile dünyada en fazla üretilen meyve grubudur. Dünyada en büyük üretici ülke Çin olup onu sırasıyla Brezilya, ABD, Hindistan ve Meksika izlemektedir. Türkiye yaklaşık 3,6 milyon ton üretim ile Akdeniz ülkeleri içerisinde önemli bir üretici konumundadır (Anonim,2016). Dünya üretiminin \% 52'si portakal, 
\% 22'si mandarin, \% 11'i limon, \% 6'sı altıntop ve kalan kısım diğer turunçgillerdir. Azot $(\mathrm{N})$, bitki gelişmesinde yaşamsal önemi olan bir bitki besin maddesidir. Azot emilimi ve dağılımı özellikle çiçeklenme ve meyve tutumu sırasında oldukça önemlidir. Meyve tutumu ve çiçeklenme, büyüme dönemlerinde yeterli azotun bulunması önemlidir. Ağaçların geç dönem büyümesini teşvik etmemek, soğuklara karşı hassasiyet kazandırmamak ve meyve kalitesi üzerine olumsuz etki etmemek için Ağustos ayı ortalarında azotlu gübre uygulamalarının tamamlanması gerekir. Yaz sonu ve sonbahar aylarındaki yüksek $\mathrm{N}$ düzeyleri kötü meyve rengi, kalın kabuk ve daha az sulu meyve oluşumuna sebep olabilir. Aşırı miktarda azot, meyve boyutu ve kalitesinin azalmasına ve olgunlaşmanın gecikmesine neden olur (Fake, 2004). Azotlu gübreler genellikle geç Şubat veya Mart ayı başlarında başlayan, en az üç veya daha fazla uygulamaya ayrılır. illk tesis maliyetlerinin azalması, verim ve kalitede artışlar sağlaması gibi sebeplerle ülkemizde basınçlı sulama sistemleri kullanımı her geçen gün artmaktadır. Bu sistemler bitki besin maddelerinin sulama suyu ile birlikte, bitki kök bölgesine istenilen miktarda ve zamanda, kontrollü bir şekilde uygulanmasına olanak sağlamaktadır. Bu sayede sulama suyu ve gübrelerin kullanım etkinliği artmakta, verim ve kalitede önemli artışlar sağlamaktadır. Mikro sulama tekniklerinde, yani damla sulama ve ağaç altı sprinklerdeki gelişmeler ve özellikle fertigasyon, bu sistemlerin narenciye dâhil olmak üzere çok yıllık bitkilerde benimsenmesini kolaylaştırmıştır. Fertigasyon ile besin alım verimliliği artırılarak, kök bölgesi altında besin yıkanması en aza indirilebilir. Böylece fertigasyon, konvansiyonel kuru gübre uygulaması ile karşılaştırıldığında, ürün verimi ve kalitesinde artışa katkıda bulunabilir (Alva ve ark., 2008). Turunç anacı üzerine aşılı Navelate portakalında, sulama ve gübrelemenin verimliliğe etkisini belirlemek amacıyla yapılan bir çalışmada, meyve tutumu sırasında toprak nem seviyesini koruyarak önemli verim artışları elde edilebileceği ve damla sulama sistemiyle $750 \mathrm{~g} \mathrm{~N}$ /ağaç/yıl uygulaması ile verimliliğin korunabileceği tespit edilmiştir (Legaz, 1981). Tarsus koşullarında azotlu gübrenin Washington portakalı verim ve kalitesine olan etkilerini araştırmak için yapılan bir çalışmada, 21 yaşındaki Washington Navel portakal ağaçlarına, 0, 400, 800, 1200 gr N/ağaç dozları uygulanmıştır. Deneme sonunda, 900 gr N/ağaç ekonomik azot dozu olarak ve azotlu gübrenin yarısının şubat ayında, kalan yarısının ise mayıs ayı ikinci haftasında ağaç tacı izdüşümüne serpme olarak verilip çapalanması önerilmiştir. Azotlu gübrelemenin portakal kabuk kalınlığına istatistiki olarak etkili olduğu sonucuna varılmıştır (Biçer ve Özel, 1986).
Valencia portakal ağaçlarında, iki sulama sisteminin (damla ve mikrosprink) meyve verim ve kalitesine etkisi değerlendirilmiştir. Damlatıcılar gövdeden 0.5 $\mathrm{m}$ ve $1.0 \mathrm{~m}$ ileri yerleştirilmiştir. Mikrosprink ile damla sulama sistemi ile aynı veya damla sulama sisteminden \%20 daha fazla hacimde su uygulanmıştır. Damla sulama sistemi ile su daha verimli kullanılmıştır. Büyüme ve verim, damlatıcıların gövdeden 1.0 m ileriye yerleştirildiği uygulamada diğer uygulamalara göre daha yüksek olmuştur (Deidda, 1992). Sulama suyu ile birlikte verilen farklı miktarlardaki azotlu gübrenin, olgun bir Yafa portakal bahçesinde meyve verim ve kalitesi üzerine etkileri araştırılmıştır. Azot, amonyum nitrat formunda ve 100, 170, $310 \mathrm{~kg} \mathrm{~N} / \mathrm{ha}$ dozlarında uygulanmıştır. Azotun, meyve verimi ve ağaç başına meyve sayısı üzerine önemli etkileri bulunmuştur. Yüksek azot oranları daha kalın kabuğa ve meyve renginin geç oluşmasına neden olmuştur (Dasberg, 1983).Valencia portakalında, yaprak $\mathrm{N}$ düzeyindeki artış; yüzde meyve suyunda ve meyve büyüklüğünde azalmaya, askorbik asid ve kabuk kalınlığında artışa, kabuk dokusunda kabalaşma ve hasat zamanında yeşil renk oluşumuna yol açmıştır (Embleton, 1978). Artan azot dozu uygulamaları; meyve suyu içeriğini ve rengini, toplam kuru madde ve asit konsantrasyonunu, hasatta kabuk kalınlığı ve yeşil meyve miktarını artırır, meyve büyüklüğü ve ağırlığını azaltır. Değişen N'lu gübre oranlarının etkilerini karşılaştırmak amacıyla, 15 yaşındaki Tarocco portakal ağaçları üzerinde yürütülen bir çalışmada, artan $\mathrm{N}$ uygulama oranları ile yaprak içeriğindeki $\mathrm{N}$ miktarının arttı̆̆ı, $\mathrm{K}$ miktarının azaldığı, P, Ca ve Mg miktarlarının az ya da çok değişmeden kaldığı, 750 g N/ağaç uygulamanın faydalı olduğu, ancak giderek artan N oranlarının meyve verim ve kalitesinde bir düşüşe yol açtığı görülmüştür (Benintende ve ark., 2009). Günümüzde portakal bahçelerinin büyük bir çoğunluğu basınçlı sulama yöntemlerine geçmiş olmasına karşın, ülkemiz koşullarında portakal ağaçlarına, bu sistemler ile uygulanması gereken azot miktarının belirlenmesine yönelik bir çalışmaya rastlanmamıştır. Tüm bunlar dikkate alındığında, bu proje ile Washington Navel portakalında, yüksek verim ve kalite için, damlama sulama sistemiyle uygulanması gereken en ekonomik azot dozunun belirlenmesi, aşırı azotlu gübre kullanımının engellenerek, çevre ve insan sağlığına verilebilecek zararların önlenmesi amaçlanmıştır.

\section{Materyal ve Yöntem}

Deneme Antalya Alanya karayolu üzerinde, Antalya ilinin $20 \mathrm{~km}$ doğusunda bulunan Batı Akdeniz Tarımsal Araştırma Enstitüsü İşletme Bölümü Arazisinde yürütülmüştür. Deneme alanına 
ait toprak özellikleri Çizelge 1'de verilmiştir. Denemenin yapıldığı alanda tipik Akdeniz İklimi hüküm sürmektedir. Denemenin yapıldığı yere ait uzun yıllar (1950-2014) ortalama iklim değerleri Çizelge 2'de verilmiştir. Deneme yerindeki uzun yıllar iklim değerleri ortalamalarına bakıldığında yıllık toplam yağış $1103.2 \mathrm{~mm}$, ortalama sıcaklık $18.4^{\circ} \mathrm{C}$ ve ortalama yağışlı gün sayısı 73 gün dür (TÜik,2015). Araştırmada bölgede yaygın olarak yetiştirilen Washington Navel portakal çeşidi kullanılmıştır (Şekil 1). Uygulama bahçesindeki ağaçlar 13 yaşında, turunç anacı üzerine aşılı olup, sıra üzeri $4 \mathrm{~m}$, sıra arası $6 \mathrm{~m}$ mesafe ile dikilidir (Şekil 2). Washington Navel, Navel grubunun ana çeşidi olan erkenci bir çeşittir. Meyvenin ortalama çapı 85 $\mathrm{mm}$ ve uzunluğu $90 \mathrm{~mm}$ 'dir. Bu nedenle meyve şekli hafif beyzi, ortalama meyve ağırlığı 216 g' dır. Bu çeşidin hasadı Kasım ayının 3. haftasında başlar ve Ocak ayı ortasına kadar devam eder (Aybak ve Kaygısız 2005). Kabuk hafif pürüzlüdür, orta kalınlıkta ve koyu portakal rengindedir. Meyve eti sıkıdır. Dilim zarları çok incedir. \% 40 usare bulunur. Meyveler taşımaya ve muhafazaya elverişlidir. Göbek oluşumu ekolojik koşullarla ilgilidir. İç kısımlara doğru göbek büyür, sahil bölgelerde göbek kapanır. Mutlak manada çekirdeksizdir. Kurak rüzgârlar ve nispi nem düşüklüğü şiddetli meyve dökümüne neden olur. Ağacı sarkık dallıdır, genç yaştan itibaren dallar eğilir. Ağaçlar genelde bu nedenle fazla büyümez (Mendilcioğlu, 1996). Deneme tesadüf blokları deneme desenine göre 3 tekerrürlü ve her tekerrürde 4 ağaç olacak şekilde kurulmuştur. Araştırmada beş farklı uygulama $10 \mathrm{~g}$ N/ağaç, 350 g N/ağaç, 700 g N/ağaç, 1050 g N/ağaç ve $1400 \mathrm{~g} \mathrm{~N} /$ ăgaç) yapılmıştır. Gübreler ŞubatAğustos ayları arasında damla sulama sistemi ile 10 gün aralıklarla, buharlaşma katsayısı hesaplanarak verilen su ile karıştırılıp ile uygulanmıştır (Şekil 3 ve Şekil 4). Verilen fosfor ve potasyum miktarları her yıl yapılan toprak, yaprak analiz sonuçlarına göre belirlenmiştir. Gerekli olan azot, fosfor ve potasyum besin elementleri aşağıdaki kimyevi gübreler; Amonyum Nitrat ( \% $33 \mathrm{~N}$ ), Mono Potasyum Fosfat ( \%52 $\mathrm{K}_{2} \mathrm{O}-\% 34 \mathrm{P}_{2} \mathrm{O}_{5}$ ), Mono Amonyum Fosfat (\% $\left.12 \mathrm{~N}-\% 61 \mathrm{P}_{2} \mathrm{O}_{5}\right)$, Potasyum Sülfat (\% $\left.50 \quad \mathrm{~K}_{2} \mathrm{O}\right)$, Magnezyum Sülfat ( $\% 16 \mathrm{MgO}$ ) kullanılarak karşılanmıştır. Ayrıca ağaçların ana bitki elementlerinden mahrum kalmaması için konular dışında ağaç başına ek gübre uygulamaları hesaplanarak tespit edilmiş ve Şubat ayından itibaren gübre uygulamaları beraber gerçekleşmiştir. Her iki yılda da hasat zamanı olan Aralık ayında, parsellerde ağaç başı verimler (kg/ağaç) alınmıştır (Şekil 5). Verilerin ekonomik olarak değerlendirilmesinde, değişen üretim masrafları dikkate alınarak Kısmi Bütçeleme analiz yöntemi kullanılmıştır (Kıral ve ark. 1999). Deneme sonucunda verim açısından uygulamalar arasındaki farklılıklar SAS istatistik paket programı kullanılarak, LSD testi ile gruplandırılmıştır. En uygun azot dozunun belirlenmesi amacıyla regresyon analizinden yararlanılmıştır.

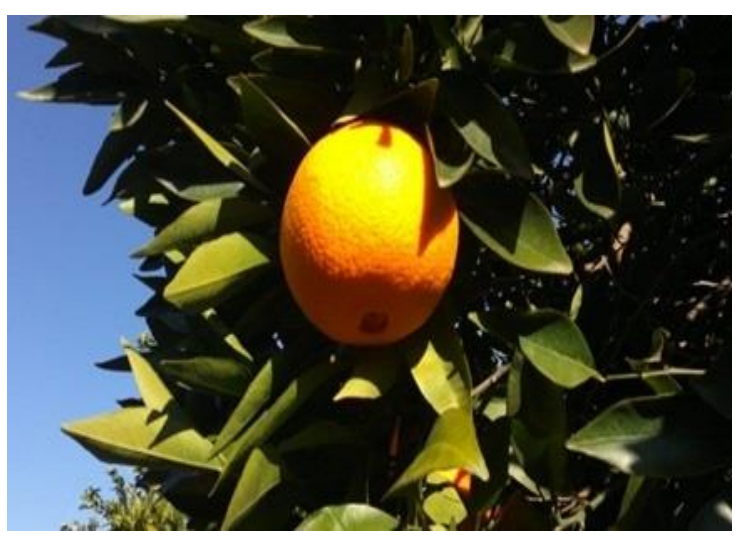

Şekil 1. Washington Navel portakal çeşidi (Antalya orijinal, 2016).

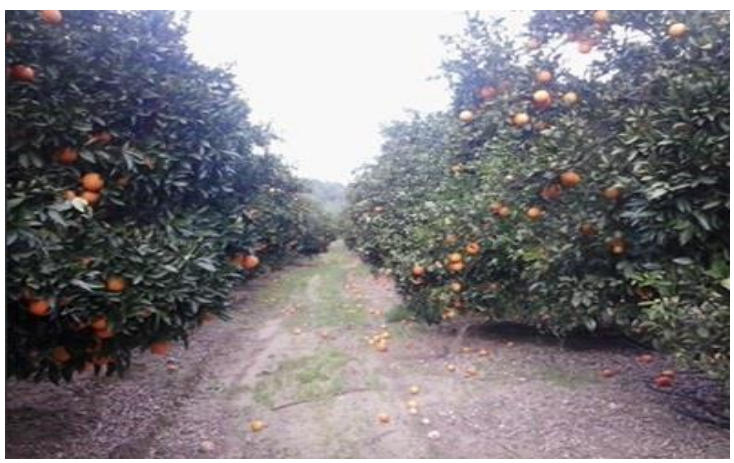

Şekil 2. Deneme alanından genel bir görünüm (Antalya orijinal, 2016).

\section{Bulgular ve Tartışma}

Araştırmada ilk iki yıl (2011 ve 2012) ön verimler alınmış, daha sonraki iki yıl uygulamalar (2013 ve 2014) yapılmıştır. 2011 ve 2012 ön verim ortalamaları Çizelge'3 de, 2013 yılı ve 2014 yılı verim ortalamaları da Çizelge 4 ve Çizelge 5 'de verilmiştir. Farklı azot dozu uygulamalarının portakalda bitki başına verime etkisi incelendiğinde; ortalamalar arasındaki farklılıkların istatistiki anlamda önemli olduğu bulunmuştur (Çizelge 6). Çizelge 6'da görüldüğü gibi yıl ortalamalarına bakıldığında en yüksek verim değeri $169.25 \mathrm{~kg}$ ile $700 \mathrm{~g} \mathrm{~N} /$ Ağaç uygulamasında saptanmıştır. Bunu sırasıyla $1050 \mathrm{~g}$ N, 350 g N uygulaması izlemiştir. En düşük verim değeri ise $146.33 \mathrm{~kg}$ ile $0 \mathrm{~g} \mathrm{~N} /$ ağaç uygulamasında saptanmıştır. Verim değerlerine ait regresyon analizi yapılmış, optimum doz $778 \mathrm{~g} \mathrm{~N}$ /ağaç olarak saptanmıştır (Şekil 6). Bu dozda alınacak ağaç başı verim ise $168.04 \mathrm{~kg}$ olarak hesaplanmıştır. Şekil 6' da da görüldüğü gibi, verimin, azot dozlarıyla ilişkisini belirten ikinci derece denklemi aşağıda görüldüğü gibidir. 


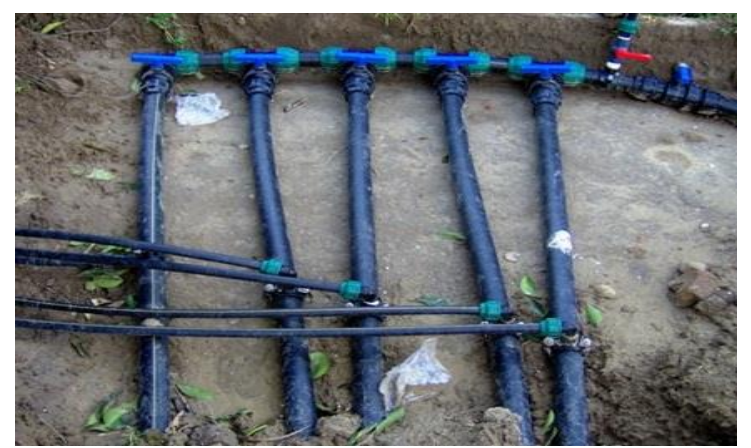

Şekil 3. Deneme alanında uygulamaları gösteren sulama sisteminden genel görünüm 1 (Antalya orijinal, 2016)

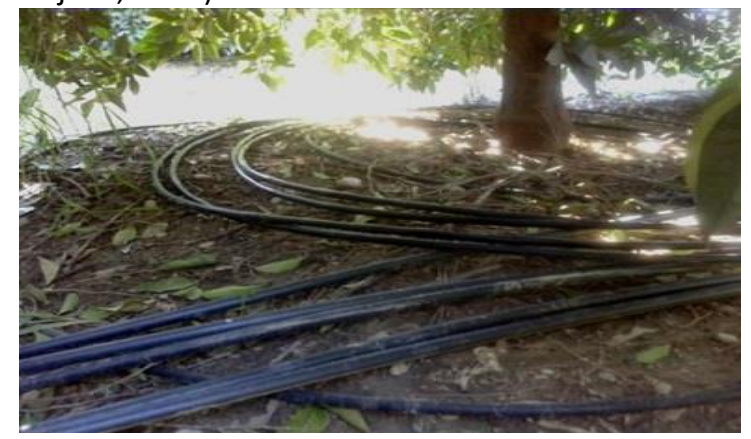

Şekil 4. Deneme alanında uygulamaları gösteren sulama sisteminden genel görünüm 2 (Antalya orijinal, 2016).

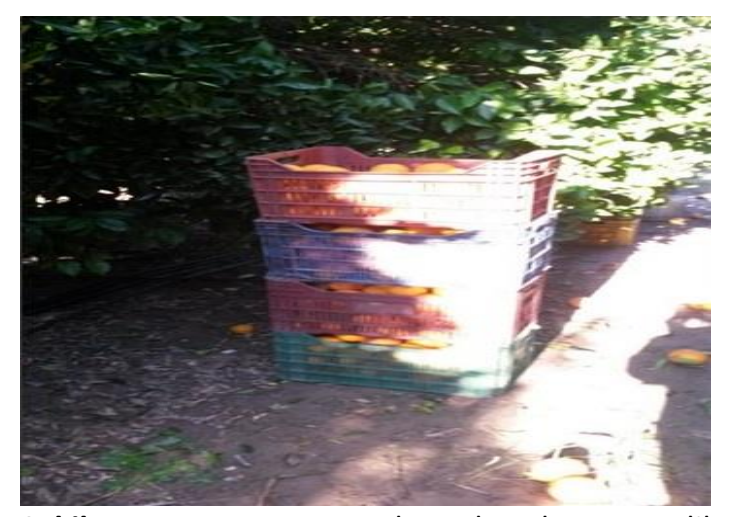

Şekil 5. Araştırma alanında hasat edilen portakallardan genel görünümler (Antalya orijinal, 2016)

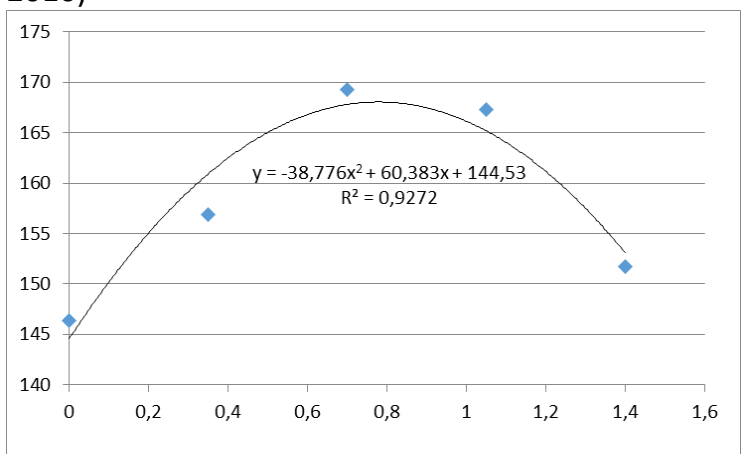

Şekil 6. Verim değerlerine ait regresyon eğrisi.

Çizelge 1. Deneme parselinin toprak özellikleri.

\begin{tabular}{llll}
\hline $\mathrm{pH}(1: 2,5)$ & 8.4 & Hafif Alkali & Richards, 1954. \\
Kireç (\%) & 30.3 & Çok Fazla Kireçli & Allison ve Moodie, 1965. \\
EC micromhos $/ \mathrm{cm}\left(25^{\circ} \mathrm{C}\right)$ & 120 & Tuzsuz & Richards, 1954. \\
Kum $(\%)$ & 53 & & Bouyoucos, 1951. \\
Kil $(\%)$ & 12 & Kumlu Tın & Bouyoucos, 1951. \\
Mil (\%) & 35 & & Bouyoucos, 1951. \\
Org. Madde (\%) & 1.5 & Az & Walkley ve Black, 1934. \\
N (Toplam) \% & 0.084 & Az & Bremner, 1965 \\
P ppm (Olsen) & 21 & Orta & Olsen ve ark., 1954 \\
K ppm & 201 & Yeterli & Jackson, 1958 \\
Ca ppm & 2963 & Yeterli & Jackson, 1958 \\
Mg ppm & 142 & Az & Jackson, 1958 \\
\hline
\end{tabular}

$Y=-38.776 X^{2}+60.383 X+144.53$

Yağcı (2011)'e göre belirtilen aşağıdaki formüle göre optimum azot dozu;

$X_{\text {tepe }}=-b / 2 a=60.383 / 2(38)=0.778 \mathrm{~kg}$ azot

Regresyon analizinde optimum doz $=778 \mathrm{~g}$

N/ağaç olarak bulunmuştur.

Verim denklemine göre ağaç başı $0.778 \mathrm{~kg}$ azot uygulandığında elde edilecek verim ise; Verim $=-38.776(0.778)^{2}+60.383(0.778)+$ $144.53=168.04 \mathrm{~kg} /$ ağaç

Araştırma sonucunda yapıla ekonomik analize göre; Washington Navel portakal çeşidine ait uygun gübre dozlarının belirlenmesi denemesinin 2013 ve 2014 yılları düzeltilmiş verilerinin ortalaması dikkate alınarak hazırlanan kısmi bütçede en fazla bürüt kar ağaç başına $700 \mathrm{~g}$ saf azot uygulamasından elde edilmiştir (Çizelge 7). Şekil 7'de bu tablodan elde edilen veriler kullanılarak brüt kar eğrisi ve bu eğriye ait üretim fonksiyonu, her bir gübre dozu için hesaplanan değişen masraf ile brüt kar arasındaki ilişkiyi göstermektedir. Düzeltilmiş ortalama veriler üzerinden yapılan marjinal gelir analizinde, alternatif durumunda olan ve brüt kar açısından bir üstündeki alternatiften daha yüksek değişen masrafa sahipken daha düşük brüt karın elde edildiği 1050 g/ağaç ve 1400 g/ağaç saf azot uygulaması alt alternatif olarak belirlenmiş ve analiz dışı bırakılmıştır (Çizelge 8). Çizelge 9'da görüldüğü gibi iki yılın düzeltilmiş veriler ortalaması 
alındığında; Washington Navel portakal üretiminde 700 g/ağaç saf azot uygulaması en fazla marjinal gelir oranına sahip olmuştur. Bu uygulamada 1 birim masrafa karşılık 9,49 birim gelir elde edilebilecektir. Ekonomik anlamda bu uygulamanın tavsiye edilmesi uygun olacaktır. Bunun yanında $350 \mathrm{~g} /$ ağaç saf azot uygulaması ise ikinci ekonomik doz olarak görülmektedir. Yapmış olduğumuz çalışma sonuçlarımız literatür özetleri ile de uyum sağlamaktadır. Legaz (1981) tarafından yapılan araştırmada 750 g N/ağaç, Biçer ve Özel (1986) tarafından Tarsus'ta yapılan çalışmada $900 \mathrm{~g}$ N/ağaç ve Benintaenda ve ark (2009) tarafından yapılan çalışmada da $750 \mathrm{~g}$ N/ağaç olduğu saptanmıştır. Bulmuş olduğumuz $778 \mathrm{~g}$ N/ağaç optimum doz miktarı bu çalışmalarla uyumludur. Ayrıca azot miktarındaki artışın verimi arttırdığı, bir noktadan sonrada verimi azalttığına dair verilen bilgilerde bizim çalışmamızda bulmuş olduğumuz verilerle uyumludur.

Çizelge 2. Antalya ili uzun yıllar iklim değerleri.

\begin{tabular}{lcc} 
Antalya & Uzun Yıllar İçinde Gerçekleşen Ortalama Değerler & Uzun Yıllar İçinde Gerçekleşen \\
$(1950-2014)$ & $\begin{array}{c}\text { En Yüksek ve En Düşük Değerler } \\
(1950-2014)\end{array}$ \\
\hline
\end{tabular}

\begin{tabular}{|c|c|c|c|c|c|c|c|c|}
\hline$\frac{\frac{1}{\pi}}{\frac{\pi}{2}}$ & 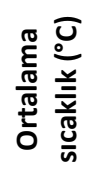 & 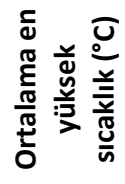 & 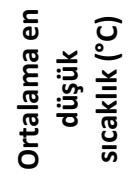 & 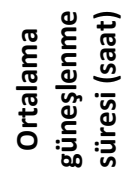 & 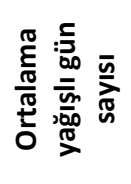 & 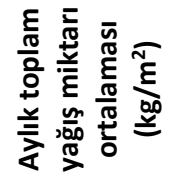 & 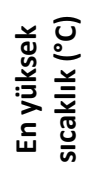 & 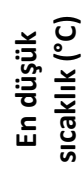 \\
\hline 1 & 9.9 & 14.9 & 6.0 & 5.2 & 12.7 & 229.9 & 23.9 & -3.4 \\
\hline 2 & 10.4 & 15.5 & 6.2 & 5.6 & 10.4 & 150.0 & 25.9 & -4.6 \\
\hline 3 & 12.7 & 18.0 & 8.0 & 6.6 & 9.0 & 102.7 & 28.6 & -1.6 \\
\hline 4 & 16.2 & 21.3 & 11.2 & 8.1 & 7.1 & 56.2 & 36.4 & -1.4 \\
\hline 5 & 20.5 & 25.5 & 15.0 & 10.6 & 5.6 & 31.9 & 38.0 & 6.7 \\
\hline 6 & 25.4 & 30.9 & 19.6 & 11.4 & 2.6 & 7.7 & 44.8 & 11.1 \\
\hline 7 & 28.4 & 34.2 & 22.7 & 12.1 & 0.6 & 2.8 & 45.0 & 14.8 \\
\hline 8 & 28.2 & 34.2 & 22.7 & 11.4 & 0.6 & 3.1 & 44.6 & 15.3 \\
\hline 9 & 24.8 & 31.2 & 19.3 & 10.0 & 1.8 & 13.5 & 42.1 & 10.6 \\
\hline 10 & 20.0 & 26.6 & 15.2 & 8.1 & 5.8 & 79.8 & 37.7 & 4.9 \\
\hline 11 & 14.9 & 21.1 & 10.6 & 6.3 & 7.8 & 136.1 & 33.0 & 0.8 \\
\hline 12 & 11.4 & 16.6 & 7.5 & 5.0 & 11.8 & 261.7 & 25.4 & -1.9 \\
\hline
\end{tabular}

Çizelge 3. Azot denemesi ağaçlar itibariyle 2011 ve 2012 yılı ortalaması olan ön verimler.

\begin{tabular}{ccccc}
\hline $\begin{array}{c}\text { Uygulamalar } \\
\text { (kg/ağaç) }\end{array}$ & \multicolumn{3}{c}{ Tekerrürler } & $\begin{array}{c}\text { Konu Ort. } \\
\text { (kg/ağaç) }\end{array}$ \\
\cline { 2 - 4 } & $\mathbf{1}$ & $\mathbf{2}$ & $\mathbf{3}$ & 110.00 \\
350 & 105.0 & 110.00 & 110.0 & 102.50 \\
700 & 102.5 & 102.50 & 110.0 & 106.67 \\
1050 & 115.0 & 106.67 & 105.0 & 105.67 \\
1400 & 105.0 & 105.67 & 110.0 & 105.00 \\
\hline
\end{tabular}

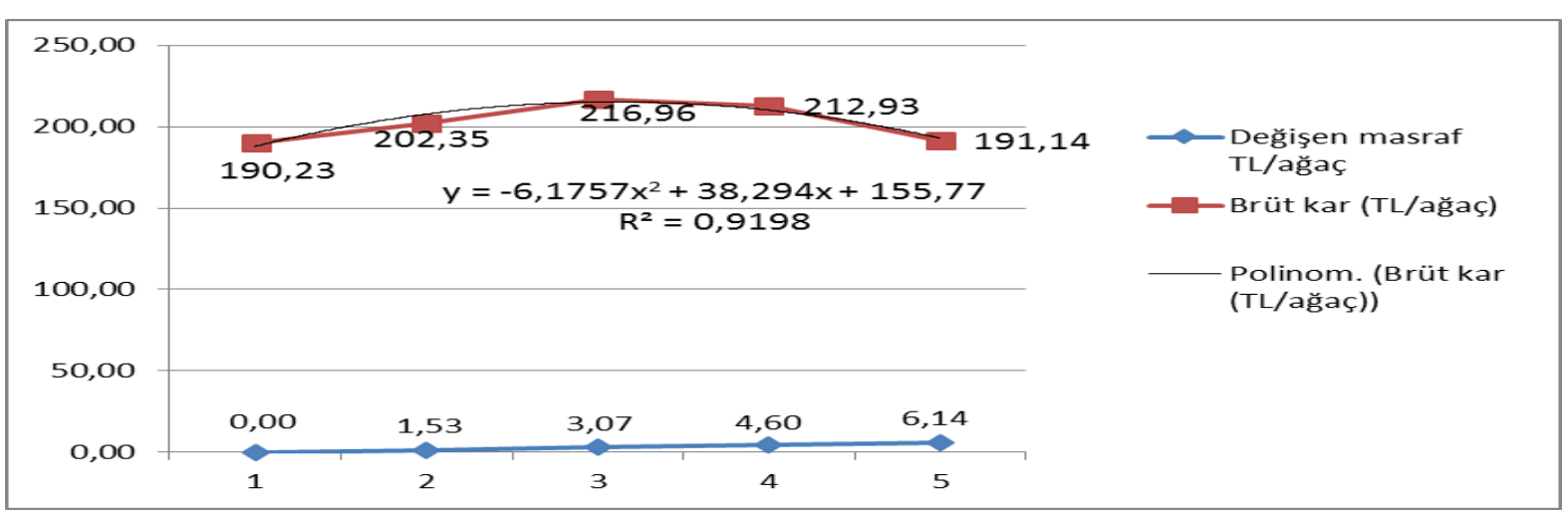

Şekil 7. Washington Navel portakal çeşidine ait gübreleme denemesinin brüt kar eğrisi ve değişen masraflar. 
Çizelge 4. Azot denemesi ağaçlar itibariyle 2013 yılı ortalaması olan ön verimler.

\begin{tabular}{ccccc}
$\begin{array}{c}\text { Uygulamalar } \\
\text { (kg/ağaç) }\end{array}$ & $\mathbf{1}$ & Tekerrürler & $\begin{array}{c}\text { Konu Ort. } \\
\text { (kg/ağaç) }\end{array}$ \\
\cline { 2 - 4 } & 133.0 & $\mathbf{2}$ & $\mathbf{3}$ & 118.67 \\
350 & 140.0 & 120.0 & 103.0 & 136.67 \\
700 & 130.0 & 155.0 & 125.0 & 141.67 \\
1050 & 151.0 & 160.0 & 140.0 & 139.33 \\
1400 & 126.5 & 132.5 & 107.0 & 125.50 \\
\hline
\end{tabular}

Çizelge 5. Azot denemesi ağaçlar itibariyle 2014 yılı verim ortalamaları.

\begin{tabular}{ccccc}
\hline $\begin{array}{c}\text { Uygulamalar } \\
\text { (kg/ağaç) }\end{array}$ & \multicolumn{3}{c}{ Tekerrürler } & $\begin{array}{c}\text { Konu Ort. } \\
\text { (kg/ağaç) }\end{array}$ \\
\cline { 2 - 4 } & $\mathbf{1}$ & $\mathbf{2}$ & $\mathbf{3}$ & 174.00 \\
350 & 160.0 & 187.0 & 175.0 & 177.17 \\
700 & 166.0 & 187.0 & 178.5 & 196.83 \\
1050 & 189.0 & 214.5 & 187.0 & 195.33 \\
1400 & 207.0 & 195.5 & 183.5 & 178.00 \\
\hline
\end{tabular}

Çizelge 6. Washington Navel portakalında farklı azot dozu uygulamalarının düzeltilmiş verim ortalamaları (20132014).

\begin{tabular}{lccc}
\hline Azot dozları (g N/ağaç) & $\begin{array}{c}\text { Ön verim Ort. (2011-2012) } \\
\text { (kg/ağaç) }\end{array}$ & $\begin{array}{c}\text { Verim Ort. (2013-2014) } \\
\text { (kg/ağaç) }\end{array}$ & $\begin{array}{c}\text { Düzeltilmiş verim Ort. } \\
\text { (kg/ağaç) }\end{array}$ \\
\hline 0 g n/ağaç (kontrol) & 110.00 & 146.33 & $146.33 \mathrm{~b}$ \\
350 g n/ağaç & 102.50 & 156.92 & $156.83 \mathrm{ab}$ \\
700 g n/ağaç & 106.67 & 169.00 & $169.25 \mathrm{a}$ \\
1050 g n/ağaç & 105.67 & 167.33 & $167.33 \mathrm{a}$ \\
1400 g n/ağaç & 105.00 & 155.25 & $151.75 \mathrm{~b}$ \\
\hline LSD \% 5 & & & 14.814 \\
\hline
\end{tabular}

Çizelge 7. Washington Navel portakal çeşidine ait gübreleme denemesinin 2013 ve 2014 yılı düzeltilmiş verimler ortalamasına göre kısmi bütçesi.

\begin{tabular}{lccccc}
\hline Masraflar & \multicolumn{5}{c}{ Gelir } \\
\hline Saf azot dozları (g N/ağaç) & $\mathbf{0}$ & $\mathbf{3 5 0}$ & $\mathbf{7 0 0}$ & $\mathbf{1 0 5 0}$ & $\mathbf{1 4 0 0}$ \\
\hline Ortalama verim (Kg/ağaç) & 146.33 & 156.83 & 169.25 & 167.33 & 151.75 \\
Üretim değeri (TL) & 190.23 & 203.88 & 220.03 & 217.53 & 197.28 \\
A. Nitrat (\% 33'lük) (Kg/ağaç) & 0.00 & 1.06 & 2.12 & 3.18 & 4.24 \\
Değişen masrafl (TL/ağaç) & 0.00 & 1.53 & 3.07 & 4.60 & 6.14 \\
Gübre maliyeti (TL/ağaç) & 0.00 & 0.95 & 1.91 & 2.86 & 3.82 \\
Gübreleme İşçiliği (TL/ağaç) & 0.00 & 0.58 & 1.16 & 1.74 & 2.32 \\
Brüt kar (TL/ağaç) & 190.23 & 202.35 & 216.96 & 212.93 & 191.14 \\
\hline
\end{tabular}

Çizelge 8. Alt alternatifler analizi (2013 ve 2014 yılı ortalaması).

\begin{tabular}{cccc}
\hline Brüt kar (TL/ağaç) & Saf azot uygulaması (g N/ağaç) & Değişen masraflar (TL/ağaç) & \\
\hline 216.96 & 700 & 3.07 & Alt alternatif \\
212.93 & 1.050 & 4.60 & Alt alternatif \\
202.35 & 350 & 1.53 & \\
191.14 & 1.400 & 6.14 & 0.00 \\
190.23 & 0.00 & 0
\end{tabular}

Çizelge 9. Washington Navel portakal çeşidine ait gübreleme denemesinin ortalama verim marjinal gelir analizi.

\begin{tabular}{ccccccc}
$\begin{array}{c}\text { Brüt kar } \\
\text { (TL/da) }\end{array}$ & $\begin{array}{c}\text { Saf azot } \\
\text { uygulaması } \\
\text { (g N/da) }\end{array}$ & $\begin{array}{c}\text { Değişen } \\
\text { masraflar } \\
\text { (TL/da) }\end{array}$ & $\begin{array}{c}\text { Brüt karda } \\
\text { marjinal artış }\end{array}$ & $\begin{array}{c}\text { Değişen masraflarda } \\
\text { marjinal artış }\end{array}$ & $\begin{array}{c}\text { Marjinal } \\
\text { gelir oranı }\end{array}$ & $\%$ \\
\hline 216.96 & 700 & 3.07 & 14.61 & 1.54 & 9.49 & 949 \\
202.35 & 350 & 1.53 & 12.12 & 1.53 & 7.92 & 792 \\
190.23 & 0.00 & 0.00 & & & & \\
\hline
\end{tabular}




\section{Sonuç ve Öneriler}

Proje verileri değerlendirildiğinde sulama suyu ile azotlu gübre uygulamasında verim açısından verilmesi gereken optimum dozu $778 \mathrm{~g}$ N/ağaç olarak üreticilere önerebiliriz.

\section{Kaynaklar}

Allison, L. E., Moodie C. D., 1965. Carbonate. In: Methods of soil analysis, (Ed. C.A. Black), American Society of Agronomy,Wisconsin, pp. 1379-1396.

Alva, A. K., Mattos Júnıor, D., Quaggıo, J. A., 2008. Advances in nitrogen fertigation of citrus. Journal of Crop Improvement 2008 Vol. 22 No. 1 pp. 121-146.

Anonim, 2016. FAO istatistikleri.

Aybak, Ç., Kaygısız, H., 2005. Narenciye Yetiştiriciliği. Hasat Yayıncılık Lmt. Şti. 219s.

Benıntende, P.G., Longo, A., Palmıerı, G., 2009. Go easy with $\mathrm{N}$-fertilisation in citrus. Informatore Agrario Vol. 65 No. 34 pp. 5154.

Bremner, J. M., Mulvaney, C. S., 1982. Nitrogentotal. In: Methods of soil analysis, Part 2 Chemical and Microbiological Properties (Ed. A.L. Page). SSSA Book series No: 9, Madison, pp. 595-622.

Biçer, Y., Özel, M., 1986. Tarsus Yöresinde Azotlu Gübrenin Washington Portakalı Verimine ve Kalitesine Etkisi. Tarsus Köy Hizmetleri Araştırma Enstitüsü Müdürlüğü Yayınları. Genel yayın no:131, rapor seri no: 73.

Bouyoucos, G. J., 1962. Hydrometer method improved for making particle size analyses of soils. Agron. J. 54: 464-465.

Dasberg, S., Bieloral, H., Emer, J., 1983. Nitrogen Fertigation on Shamouti Orange. Plant and Soil, Vol. 75 No. 1 pp. 41-49.

Deidda, P., Filigheddu, M.R., Dettori, S., 1992. Progress report on the influence of irrigation system on yield and fruit quality in Valencia orange (Citrus sinensis (L.) Osbeck). Proceedings of the International Society of Citriculture: Volume 2. Cultural practices, diseases and their control: 7th International Citrus Congress, Acireale, Italy, 8-13 March.

Embleton, T.W., Jones, W.W., Pallares, C., Platt, R.G., 1978. Effects of fertilization of citrus on fruit quality and ground water nitrate pollution potential. Proceedings of the International Society of Citriculture.

Fake, C., 2004. Fertilizing Citrus in The Foothills. Üniversty of California Cooperative Extension.Newsletters, Publication Number:31011C.
Jackson, M., 1958. Soil chemical analysis. p. 1-498. Prentice-Hall, Inc. Englewood Cliffs, New Jersey, USA.

Kıral, T., Kasnakoğlu, H., Tatlıdil, F.F., Fidan H., Gündoğmuş, E., 1999. Tarımsal Ürünler İçin Maliyet Hesaplama Metodolojisi ve Veri Tabanı Rehberi, Tarım Ekonomisi Araştırma Enstitüsü Yayın No:37, Ankara.

Legaz, F., Ibañez, R., Barreda, D. G. De Ve Prımo Mıllo, E. 1981 (a) Influence of irrigation and fertilization on productivity of the 'Navelate' sweet orange. Proceedings of the International Society of Citriculture, 1981. Volume 2. 1983 pp. 591-595.

Legaz, F., Barreda, D. G. De, Zaragoza, S., Primo Millo, E.,1981(b). Interactions between water amounts and fertilizer applied through a drip irrigation system in clementine and satsuma mandarins.

Mendilcioğlu, K., 1996. Subtropik İklim Meyveleri (Turunçgiller). Ege Üniversitesi

Olsen, S.R., Dean, L.A., Phosphorus, Ed. C.A. Black, (1965). In: Methods of Soil Analyses, Part II American Society of Agronomy Inc. Publisher Madison. Wisconsin. USA: 1035-1049.

Richards, L.A. (Ed.) 1954. Diagnosis and Improvement of saline and alkali soils. USDA Agriculture Handbook60. Washington D.C.

Walkley, A., Black, L.A., 1934. An examination of degtjareff method for determining soil organic matter and aproposed modification of the chromic acid titration method. Soil Sci. 39: 29-38.

TÜik, 2015. Türkiye İstatistik Kurumu. Tarım, Bitkisel Üretim İstatistikleri http://www.tuik.gov.tr/bitkiselapp/bitkisel. 